\title{
Reduced Paneth cell antimicrobial protein levels correlate with activation of the unfolded protein response in the gut of obese individuals.
}

Citation for published version (APA):

Hodin, C. M. I., Verdam, F. J., Grootjans, J., Rensen, S. S. M., Verheyen, F. K., Dejong, C. H. C., Buurman, W. A., Greve, J. W., \& Lenaerts, K. (2011). Reduced Paneth cell antimicrobial protein levels correlate with activation of the unfolded protein response in the gut of obese individuals. Journal of Pathology, 225(2), 276-284. https://doi.org/10.1002/path.2917

Document status and date:

Published: 01/01/2011

DOI:

10.1002/path.2917

Document Version:

Publisher's PDF, also known as Version of record

Document license:

Taverne

Please check the document version of this publication:

- A submitted manuscript is the version of the article upon submission and before peer-review. There can be important differences between the submitted version and the official published version of record.

People interested in the research are advised to contact the author for the final version of the publication, or visit the DOI to the publisher's website.

- The final author version and the galley proof are versions of the publication after peer review.

- The final published version features the final layout of the paper including the volume, issue and page numbers.

Link to publication

\footnotetext{
General rights rights.

- You may freely distribute the URL identifying the publication in the public portal. please follow below link for the End User Agreement:

www.umlib.nl/taverne-license

Take down policy

If you believe that this document breaches copyright please contact us at:

repository@maastrichtuniversity.nl

providing details and we will investigate your claim.
}

Copyright and moral rights for the publications made accessible in the public portal are retained by the authors and/or other copyright owners and it is a condition of accessing publications that users recognise and abide by the legal requirements associated with these

- Users may download and print one copy of any publication from the public portal for the purpose of private study or research.

- You may not further distribute the material or use it for any profit-making activity or commercial gain

If the publication is distributed under the terms of Article 25fa of the Dutch Copyright Act, indicated by the "Taverne" license above, 


\title{
Reduced Paneth cell antimicrobial protein levels correlate with activation of the unfolded protein response in the gut of obese individuals
}

\author{
Caroline M Hodin,' Froukje J Verdam,' Joep Grootjans,' Sander S Rensen,' Fons K Verheyen, ${ }^{2}$ Cornelis \\ HC Dejong,' Wim A Buurman,' ${ }^{*}$ Jan Willem Greve't and Kaatje Lenaerts' \\ I NUTRIM School for Nutrition, Toxicology and Metabolism, Department of Surgery, Maastricht University Medical Centre, Maastricht, The \\ Netherlands \\ 2 Department of Molecular Cell Biology, Maastricht University Medical Centre, Maastricht, The Netherlands
}

*Correspondence to: Wim A Buurman, Department of Surgery, Maastricht University Medical Centre, PO Box 616, 6200 MD Maastricht, The Netherlands. e-mail:w.buurman@maastrichtuniversity.nl

†Current address: Department of Surgery, Atrium Medical Centre, Heerlen, The Netherlands.

\begin{abstract}
The intestinal microbiota is increasingly acknowledged to play a crucial role in the development of obesity. A shift in intestinal microbiota composition favouring the presence of Firmicutes over Bacteroidetes has been observed in obese subjects. A similar shift has been reported in mice with deficiency of active Paneth cell $\alpha$-defensins. We aimed at investigating changes in Paneth cell antimicrobial levels in the gut of obese subjects. Next, we studied activation of the unfolded protein response (UPR) as a possible mechanism involved in altered Paneth cell function. Paneth cell numbers were counted in jejunal sections of 15 severely obese (BMI > 35) and 15 normal weight subjects. Expression of Paneth cell antimicrobials human $\alpha$-defensin 5 (HD5) and lysozyme were investigated using immunohistochemistry, qPCR, and western blot. Activation of the UPR was assessed with western blot. Severely obese subjects showed decreased protein levels of both HD5 and lysozyme, while Paneth cell numbers were unchanged. Lysozyme protein levels correlated inversely with BMI. Increased expression of HD5 (DEFA5) and lysozyme (LYZ) transcripts in the intestine of obese subjects prompted us to investigate a possible translational block caused by UPR activation. Binding protein (BiP) and activating transcription factor 4 (ATF4) levels were increased, confirming activation of the UPR in the gut of obese subjects. Furthermore, levels of both proteins correlated with BMI. Involvement of the UPR in the lowered antimicrobial protein levels in obese subjects was strongly suggested by a negative correlation between BiP levels and lysozyme levels. Additionally, indications of ER stress were apparent in Paneth cells of obese subjects. Our findings provide the first evidence for altered Paneth cell function in obesity, which may have important implications for the obesity-associated shift in microbiota composition. In addition, we show activation of the UPR in the intestine of obese subjects, which may underlie the observed Paneth cell compromise.

Copyright $\odot 201$ I Pathological Society of Great Britain and Ireland. Published by John Wiley \& Sons, Ltd.
\end{abstract}

Keywords: Paneth cell; obesity; antimicrobial proteins; unfolded protein response

Received I8 January 201 I; Revised 29 March 20I I; Accepted 10 April 20II

No conflicts of interest were declared.

\section{Introduction}

The intestine is colonized by a complex microbiota, which plays an important role in physiological and homeostatic functions. A close relationship between the intestinal microbiota and obesity has been revealed. First, it has been shown that germ-free animals are protected from diet-induced obesity $[1,2]$. Second, colonization of the gut of lean germ-free mice with the intestinal microbiota of obese mice results in a significant weight gain of these mice, while this was not observed when germ-free lean mice were inoculated with the intestinal flora of lean donor mice [3]. The underlying mechanisms explaining these observations were suggested to be increased bacteria-mediated energy harvest from the diet and the ability of bacteria to influence host lipid metabolism, thereby affecting energy expenditure and storage [1,2]. Finally, obesityrelated changes in the composition of the microbiota have been described in both man and animals [3-5]. A large shift in microbiota favouring the presence of Firmicutes over Bacteroidetes was reported in obesity [3-5], which remarkably reverted to normal after weight loss [5]. Strikingly, a similar shift in microbiota composition was observed in mice deficient in the active form of the antimicrobial peptides $\alpha$-defensins [6]. On the contrary, mice overexpressing $\alpha$-defensins showed a higher percentage of Bacteroidetes and a 
lower percentage of Firmicutes [6,7]. In the gut, $\alpha$ defensins are produced by Paneth cells. These cells, residing in the crypts of the small intestine, produce large amounts of antimicrobials including human $\alpha$ defensin 5 (HD5) and lysozyme, which makes them key players in controlling the microbiota composition of both the small and the large intestine $[8,11]$.

In view of the major impact of Paneth cell antimicrobials on intestinal microbiota composition and the striking similarity between microbiota alterations in mice defective in active $\alpha$-defensins and in obesity, we hypothesized that compromised Paneth cell function might underlie the microbial shift described in obese subjects.

We report a decrease in the protein expression of both HD5 and lysozyme in the jejunum of obese subjects, compared with normal weight controls. Moreover, we show activation of the unfolded protein response (UPR) in the small intestine of obese subjects and indications of endoplasmic reticulum (ER) stress in Paneth cells, which we propose to be a putative mechanism underlying Paneth cell compromise. Our study is the first to suggest that a host factor is involved in the obesity-associated intestinal microbial shift.

\section{Materials and methods}

\section{Ethics}

The study was approved by the Medical Ethical Committee of Maastricht University Medical Centre and conducted according to the revised version of the Declaration of Helsinki (October 2008, Seoul). Written consent of all patients was obtained.

\section{Study population and tissue collection}

A sequentially included cohort of 15 severely obese subjects $(\mathrm{BMI}>35)$ undergoing gastric bypass surgery was studied retrospectively. Exclusion criteria for this study were acute or chronic inflammatory diseases, degenerative diseases, more than $10 \mathrm{~g}$ of alcohol consumption per day, and use of anti-inflammatory drugs. During surgery, jejunal biopsies were obtained and divided into two pieces. Control jejunal biopsies were obtained from 15 consecutive patients undergoing pancreatoduodenectomy. During this procedure, a variable length of jejunum is routinely resected in continuity with the head of the pancreas and duodenum. One piece of tissue was immediately formalin-fixed and embedded in paraffin, another piece was snap-frozen in liquid nitrogen. Snap-frozen samples were stored at $-80^{\circ} \mathrm{C}$ until further processing for western blot or qPCR. Patient characteristics are summarized in Table 1.

\section{Antibodies and reagents}

The antibodies and reagents used are described in the Supporting information, Supplementary materials and methods.
Table 1. Patient characteristics

$\begin{array}{lcc}\text { Characteristic } & \text { Obese }(n=15) & \text { Normal weight }(n=15) \\ \text { Sex (male : female) } & 2: 13 & 9: 6^{*} \\ \text { Age (years) } & 43.3 \pm 2.7 & 58.9 \pm 3.3^{\dagger} \\ \text { BMI }\left(\mathrm{kg} / \mathrm{m}^{2}\right) & 43.7 \pm 1.6 & 24.6 \pm 1.5^{\dagger}\end{array}$

${ }^{*} p<0.05 .{ }^{+} p<0.01$.

\section{Histology and immunohistochemistry}

Tissue sections were cut at $4 \mu \mathrm{m}$, deparaffinized in xylene, and rehydrated through graded ethanols to distilled water. For quantification of Paneth cell number, sections of all test and control subjects were stained with haematoxylin and eosin (H\&E), and cells were counted in 40 crypts in representative microscopic fields $(200 \times)(n=15$ per group). For immunohistochemistry, endogenous peroxidase was quenched with $0.3 \% \mathrm{H}_{2} \mathrm{O}_{2}$ in methanol. After blocking nonspecific antibody binding with $5 \%$ bovine serum albumin, sections were incubated with specific antibodies to human lysozyme $(1 \mu \mathrm{g} / \mathrm{ml}$ in $0.1 \% \mathrm{BSA} / \mathrm{PBS})$ and HD5 $(1 \mu \mathrm{g} / \mathrm{ml}$ in $0.1 \% \mathrm{BSA} / \mathrm{PBS})$ at room temperature for $60 \mathrm{~min}$. Next, an appropriate biotinconjugated secondary antibody $(1.5 \mu \mathrm{g} / \mathrm{ml}$ in $0.1 \%$ BSA/PBS) was applied. Binding of the primary antibody was visualized with a streptavidin-biotin HRP system and 3-amino-9-ethylcarbazole. Nuclei were stained with haematoxylin and stained sections were mounted in aqueous mounting medium (Dakocytomation, Glostrup, Denmark). To avoid inter-assay variability, immunohistochemistry was performed on all study subjects simultaneously.

\section{Western blotting}

For western blot, full-thickness tissue samples were homogenized in lysis buffer $(200 \mathrm{mM} \mathrm{NaCl}, 10 \mathrm{mM}$ Tris buffer, $5 \mathrm{mM}$ EDTA, $10 \%$ glycerol, and $1 \%$ NP-40) using a Biospec mini-beadbeater and glass beads (Bartlesville, OK, USA). Samples were centrifuged at $18000 \mathrm{~g}$ for $15 \mathrm{~min}$ at $4{ }^{\circ} \mathrm{C}$. The protein concentration of supernatants was determined using a BCA protein assay kit (Pierce Thermo Fisher Scientific Inc, Rockford, IL, USA). Protein (10 $\mu \mathrm{g})$ was heated for $5 \mathrm{~min}$ in reducing SDS sample buffer, separated by SDS-PAGE on a $15 \%$ polyacrylamide gel, and transferred onto polyvinylidene fluoride membrane (Immobilon P, Millipore, Bedford, MA, USA). After transfer of proteins, membranes were blocked with phosphate-buffered saline (PBS) supplemented with $5 \%$ non-fat dry milk. Next, antibody incubation was performed overnight at $4{ }^{\circ} \mathrm{C}$ in $\mathrm{PBS}-0.05 \%$ Tween (PBST) supplemented with $3 \%$ non-fat dry milk, with anti-lysozyme $(1 \mu \mathrm{g} / \mathrm{ml})$, anti-BiP $(0.5 \mu \mathrm{g} / \mathrm{ml})$, antiATF4 $(0.2 \mu \mathrm{g} / \mathrm{ml})$ or anti-GADD34 $(0.8 \mu \mathrm{g} / \mathrm{ml})$ antibody. To assess equal protein loading, membranes were reprobed with anti- $\beta$-actin $(1 \mu \mathrm{g} / \mathrm{ml})$ antibodies. After washing with PBST, membranes were incubated with an appropriate HRP-conjugated secondary antibody $(0.1 \mu \mathrm{g} / \mathrm{ml})$ for $90 \mathrm{~min}$ at room temperature. Signals 
were detected using the chemiluminescent substrate Supersignal West Pico (Pierce Thermo Fisher Scientific Inc) on blue X-ray film (Fuji, SuperRX, Tokyo, Japan). Band intensity was semi-quantitatively analyzed using Quantity One (Bio-Rad, Hercules, CA, USA).

\section{Quantitative polymerase chain reaction ( $q P C R$ )}

RNA was extracted from full-thickness jejunal tissue using TRI reagent according to the manufacturer's protocol. RNA samples were treated with DNAse (Promega, Madison, WI, USA) to ensure the removal of contaminating genomic DNA. RNA concentration was determined by Nanodrop (Nanodrop, Wilmington, DE, USA) and $750 \mathrm{ng}$ of RNA was used as the template for reverse transcription in a cDNA synthesis reaction using iScript cDNA synthesis kit (Bio$\mathrm{Rad})$. qPCR reactions were conducted in a volume of $20 \mu \mathrm{l}$ containing $10 \mathrm{ng}$ of cDNA, $1 \times$ Absolute qPCR SYBR Green Fluorescein Mix (Westburg, Leusden, The Netherlands), and $150 \mathrm{nM}$ of gene-specific forward and reverse primers. The sequences of the primers used are provided in the Supporting information, Supplementary Table 1. Gene expression levels of lysozyme (LYZ) and HD5 (DEFA5) were determined with iQ5 software (Bio-Rad) using a $\Delta$-Ct relative quantification model. The geometric mean of the expression levels of two reference genes, cyclophilin A (PPIA) and $\beta 2$ microglobulin $(B 2 M)$ was calculated and used as a normalization factor.

\section{Electron microscopy (EM)}

For electron microscopy scanning, jejunal tissue $(n=$ 4 per group) was immersed in $2.5 \%$ glutaraldehyde in $0.1 \mathrm{M}$ sodium phosphate buffer at $\mathrm{pH}$ 7.4. Next, samples were rinsed in cacodylate buffer and postfixed in $1 \% \mathrm{OsO}_{4}$ in $0.067 \mathrm{M}$ cacodylate buffer $(\mathrm{pH} 7.4)$ supplemented with $1.5 \%$ potassium ferrocyanide at $4{ }^{\circ} \mathrm{C}$ for 1 hour. After a short rinse in cacodylate buffer, dehydration was carried out in graded ethanol series, followed by embedding in Epon. Ultrathin sections were stained with uranyl acetate and lead citrate and examined with a Philips CM 100 electron microscope at an accelerating voltage of $80 \mathrm{KV}$.

\section{Statistical analysis}

Statistical analysis was performed using Prism 5.02 for Windows (GraphPad Software Inc, San Diego, CA, USA). A two-tailed Mann-Whitney $U$-test was used to detect differences between groups. Data are presented as mean \pm standard error of the mean (SEM). Spearman's correlation coefficient was determined to study associations between variables. Differences were considered statistically significant at $p<0.05$. Multivariate linear regression analysis was used to test for confounding in the data analysis.

\section{Results}

\section{Reduced levels of Paneth cell antimicrobials in obese subjects}

To study potential Paneth cell alterations in obesity, we first investigated HD5 expression in the jejunum of obese and normal weight control subjects. Immunohistochemical staining for HD5 showed intense staining in Paneth cell granules of normal weight subjects, whereas staining for this antimicrobial protein was substantially reduced in the jejunum of obese individuals (Figure 1A).

Next, to investigate whether the reduction in HD5 expression in obese subjects was a result of generalized Paneth cell compromise, we studied lysozyme levels, another highly expressed antimicrobial protein in Paneth cells. Similar to HD5, lysozyme was abundantly present in granules of Paneth cells of normal weight control subjects, while staining was strongly diminished in obesity (Figure 1B). Semi-quantitative analysis by western blot confirmed a reduced amount of lysozyme in the small intestine of obese patients compared with intestinal samples from normal weight subjects (Figure 1C; $p<0.05$ ). A relationship between obesity and antimicrobial protein expression in the gut of obese subjects was demonstrated by an inverse correlation between BMI and lysozyme protein levels (Figure 1D; $r_{\mathrm{s}}=-0.42, p<0.05$ ).

Quantification of Paneth cells revealed equal numbers in the jejunum of both study groups, excluding the possibility that the observed decrease in antimicrobial protein expression in Paneth cells was caused by reduced cell numbers (Figure 2). Taken together, these data indicate that antimicrobial protein levels are reduced in the Paneth cells of obese subjects.

\section{Enhanced expression of Paneth cell antimicrobial genes in obesity}

To investigate whether the reduced antimicrobial protein levels in obese subjects were due to reduced gene expression, we quantified the mRNA expression of HD5 (DEFA5) and lysozyme (LYZ). Surprisingly, qPCR data showed 2.6-fold increased expression of HD5 (Figure 3A; $p<0.01$ ) and 1.6-fold increased expression of lysozyme (Figure $3 \mathrm{~B} ; p=0.15$ ) in the jejunal tissue of obese subjects compared with normal weight controls. Since the discrepancy seen in protein expression and mRNA expression of HD5 and lysozyme could point towards a translational arrest due to ER stress, we next assessed activation of the UPR.

\section{Activation of the UPR and indications of ER stress in the small intestine of obese subjects}

ER stress arises from circumstances resulting in the accumulation of misfolded or unfolded proteins in the ER. Upon ER stress, the UPR is activated, which is aimed at restoring ER homeostasis. To investigate the putative involvement of ER stress in the reduced 
A
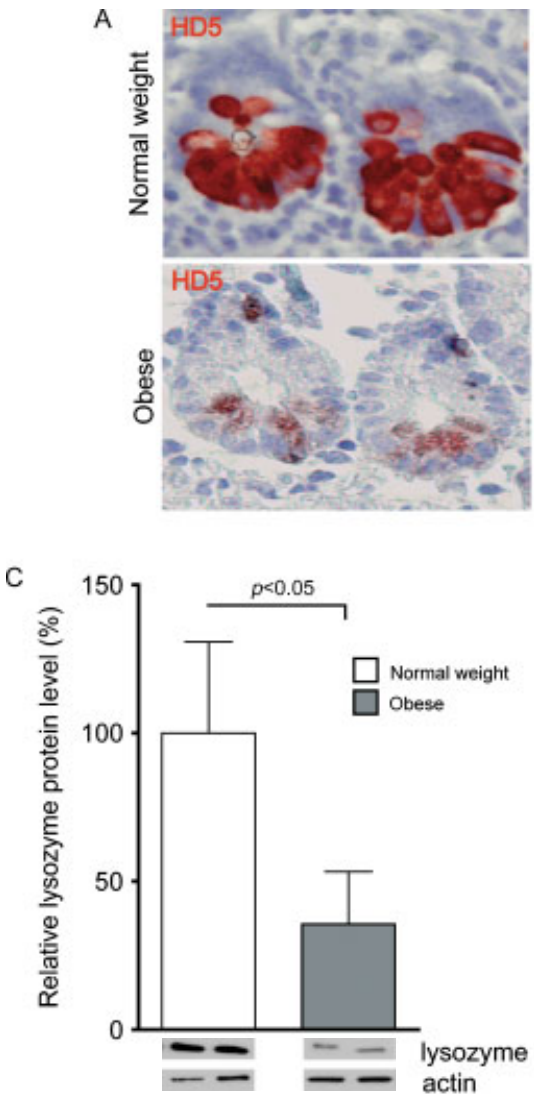

B

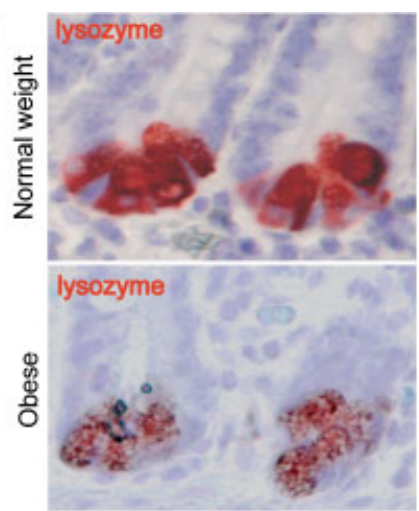

D

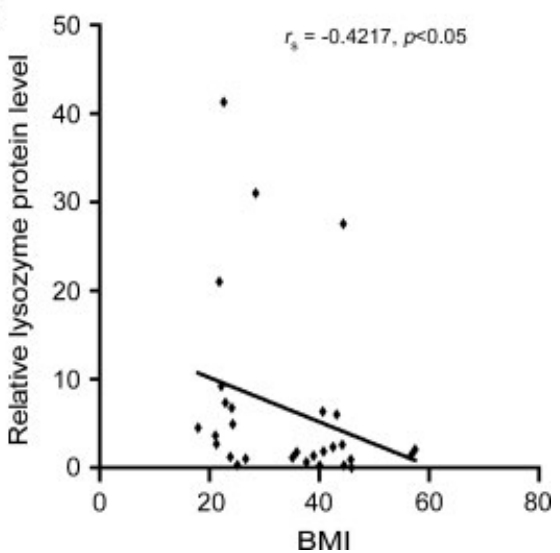

Figure 1. HD5 and lysozyme levels are decreased in the Paneth cells of obese subjects. (A) Immunohistochemistry for HD5 in the jejunum of normal weight (upper panel) versus obese (lower panel) subjects showed strongly reduced staining in the Paneth cells of obese subjects. (B) Immunohistochemistry for lysozyme in the jejunum of normal weight (upper panel) versus obese subjects (lower panel) showed markedly reduced expression in the Paneth cells from obese subjects. (C) Western blot analysis revealed a significant decrease in the jejunal levels of lysozyme in obese subjects compared with normal weight subjects, confirming the staining results $(p<0.05)$. $\beta$-Actin was used to assess equal protein loading. (D) Jejunal lysozyme content was inversely correlated with BMI $\left(r_{\mathrm{s}}=-0.42, p<0.05\right)$. The histology shown is representative for all tissue samples studied (original magnification $200 \times$ ).

A

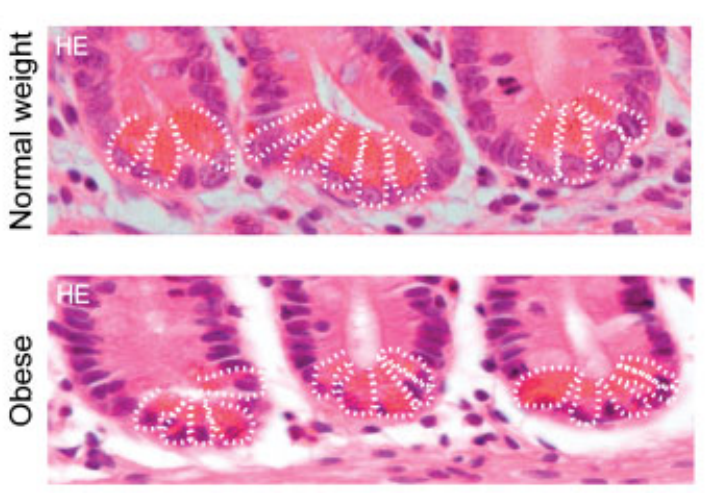

B

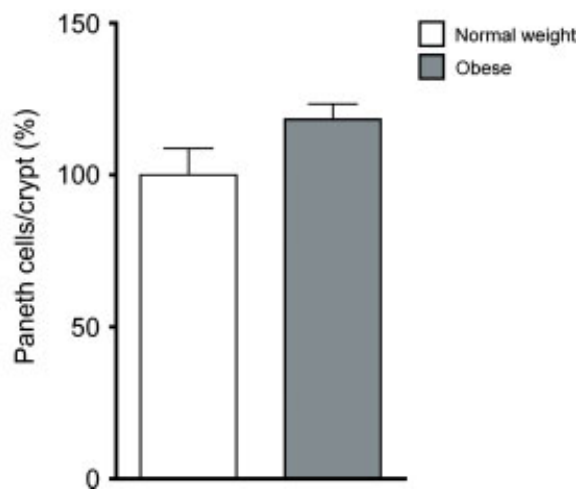

Figure 2. Equal Paneth cell numbers in the jejunum of obese and normal weight subjects. (A) H\&tE staining demonstrated equal numbers of Paneth cells in the jejunal crypts of normal weight and obese subjects. (B) Quantification of the number of Paneth cells present in the jejunum of obese subjects showed no difference in Paneth cell count compared with control tissues. The histology shown is representative for all tissue samples studied (original magnification 200x).

antimicrobial protein expression by Paneth cells in obesity, activation of the protein kinase RNA-like endoplasmic reticulum kinase (PERK) pathway was assessed. This branch of the UPR is responsible for a translational arrest which reduces protein load to the ER and thus alleviates ER stress [12]. We first studied binding protein (BiP), an important player in the initiation and maintenance of the UPR [13]. BiP levels were significantly increased in jejunal samples of obese patients compared with normal weight subjects, signifying activation of the UPR (Figures 4A and 4B; $p<$ 0.05). A correlation between BMI and BiP levels was found and further indicated a relationship between obesity and activation of the UPR in the gut (Figure 4B, right panel; $\left.r_{\mathrm{s}}=0.45, p<0.05\right)$. In addition, protein levels of activating transcription factor 4 (ATF4), which 

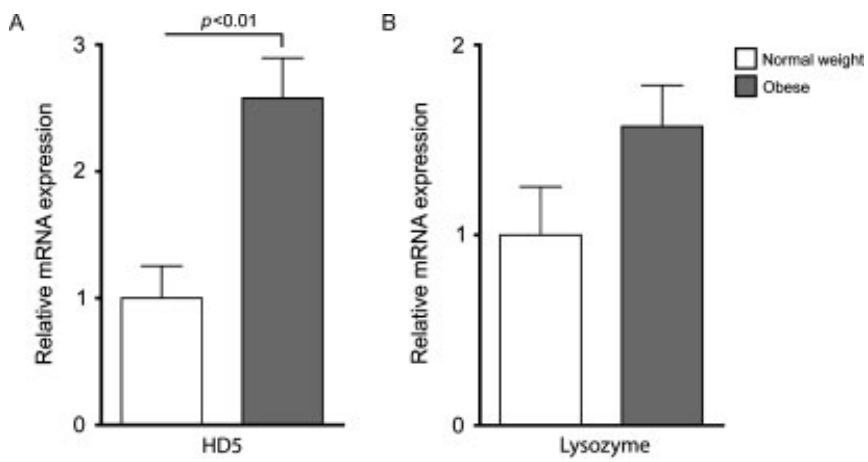

Figure 3. Increased HD5 and lysozyme gene expression in the jejunum of obese subjects. (A) qPCR analysis showed a 2.6-fold increase in HD5 (DEFA5) mRNA $(p<0.01)$ and (B) a 1.6-fold increase in the levels of lysozyme $(L Y Z)$ mRNA $(p=0.15, n s)$.

induces transcription of downstream mediators in the PERK pathway, were also significantly increased in obese subjects (Figures 4A and 4C; $p<0.05$ ). ATF4 protein levels correlated with BMI as well, providing additional evidence for a relationship between obesity and UPR activation (Figure 4C, right panel; $r_{\mathrm{s}}=0.41$, $p<0.05)$. We next analyzed the protein expression of growth arrest and DNA damage-inducible protein 34 (GADD34), a downstream target of ATF4 that provides a negative feedback loop to the PERK pathway to reinitiate protein translation. GADD34 levels were similar in both study groups (Figures 4A and 4D). ER compromise was studied using EM to assess the contribution of Paneth cells to the results obtained by western blot on UPR activation. Indeed, Paneth cells of obese subjects showed an enlarged ER with vacuoles (Figure 5B), indicative of ER stress, whereas a normally structured ER was found in Paneth cells of normal weight subjects (Figure 5A).

Importantly, involvement of the UPR in the lowered antimicrobial protein levels in obese subjects was strongly suggested by a negative correlation between BiP levels and lysozyme levels (Figure 6; $r_{\mathrm{s}}=-0.39$, $p<0.05)$.

The age- and gender-differences between the study groups do not confound the results on UPR activation and Paneth cell products, as assessed by multivariate analysis ( $p>0.05$ for all variables tested).

All in all, these results suggest that activation of the UPR contributes to the diminished expression of antimicrobial proteins in the jejunum of obese individuals.

\section{Discussion}

Over the past decade, the influence of Paneth cells on controlling intestinal microbiota composition and limiting bacterial translocation has become increasingly clear $[6,10,14]$. Intestinal microbiota on its part has been shown to play an important role in obesity. In this study, we provide the first evidence for altered Paneth cell properties in human obesity. We show decreased levels of the crucial Paneth cell antimicrobials HD5 and lysozyme in the jejunum of obese subjects compared with normal weight subjects. In addition, we provide new insight into the mechanisms that could account for this phenomenon showing activation of the UPR in the gut of obese subjects for the first time.

Changes in $\alpha$-defensin levels, as also described in Crohn's disease [8], have been shown to influence the composition of the intestinal microbiota in mice [6,8]. A reduction in $\alpha$-defensin levels has been shown to result in a higher percentage of Firmicutes and a lower percentage of Bacteroidetes in the small intestine [6]. Moreover, Paneth cell-produced antimicrobial proteins were proven to act in the colon [11]. Interestingly, a similar Firmicutes-Bacteroidetes shift has been observed in the colon of obese subjects [5]. The decreased HD5 expression in the gut of obese subjects that we observed could therefore very well explain the reported shift in bacterial composition. However, the composition of the intestinal microbiota in our study groups could not be investigated since the clinical study from which the tissue samples were derived did not include faecal samples and this remains subject for future studies. Alternatively, it should be noted that changes in the expression of antimicrobial peptides could occur secondary to alterations in the composition of the intestinal microbiota.

Since changes in the gut microbiota have been implicated in the obesity-associated increase in intestinal permeability and metabolic endotoxaemia, we hypothesize that disturbed Paneth cell function may underlie these phenomena $[15,16]$. Furthermore, increased intestinal permeability in obesity has been suggested to lead to enterogenous endotoxaemia contributing to non-alcoholic steatohepatitis [17-20].

In addition to the change in microbiota composition, a generalized Paneth cell malfunction might contribute to these obesity-related complications in other ways. For example, Paneth cells prevent bacterial translocation in the healthy intestine and act as a second line of defence in limiting bacterial translocation in situations of physical intestinal barrier loss [10,21]. An overall reduction in antimicrobial protein production by Paneth cells might therefore play an important role in facilitating bacterial translocation, as has been suggested to occur in obesity $[15,22,23]$, thereby adding to the role of an increased intestinal permeability. 
A

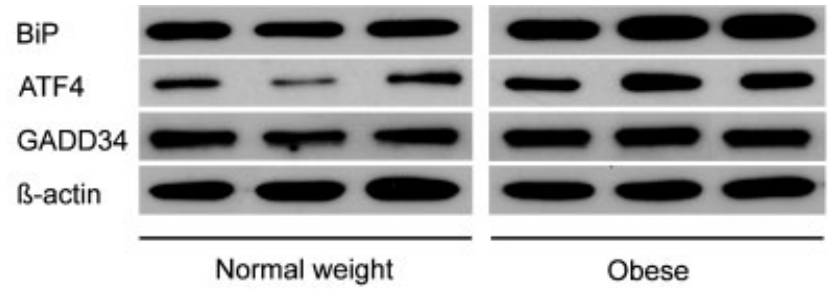

B
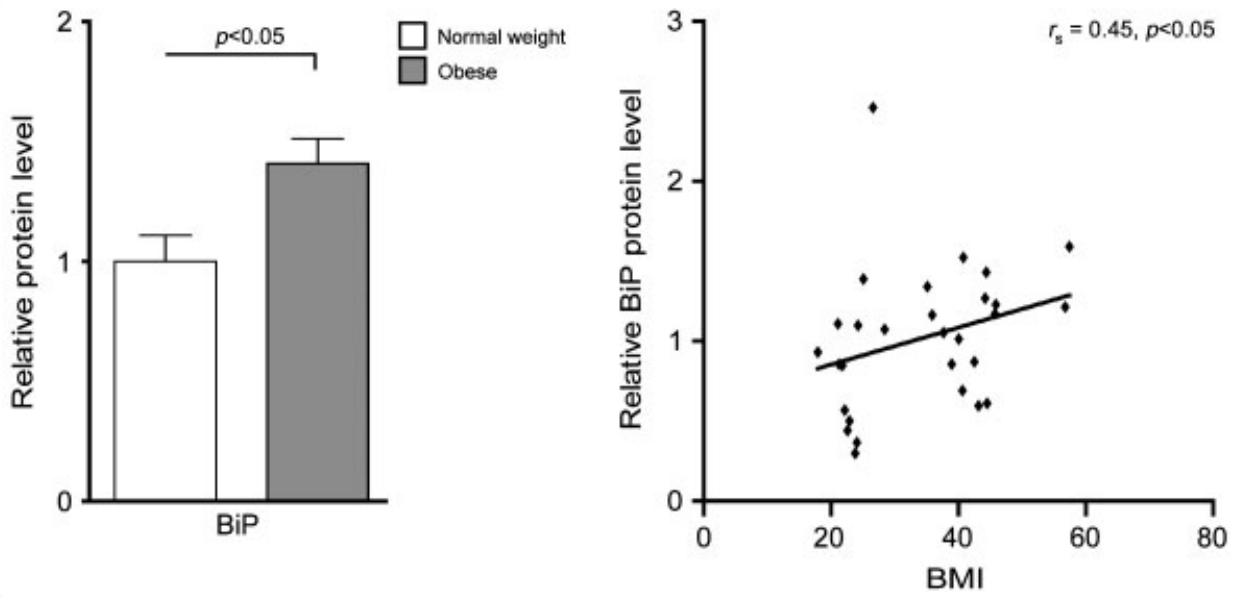

C
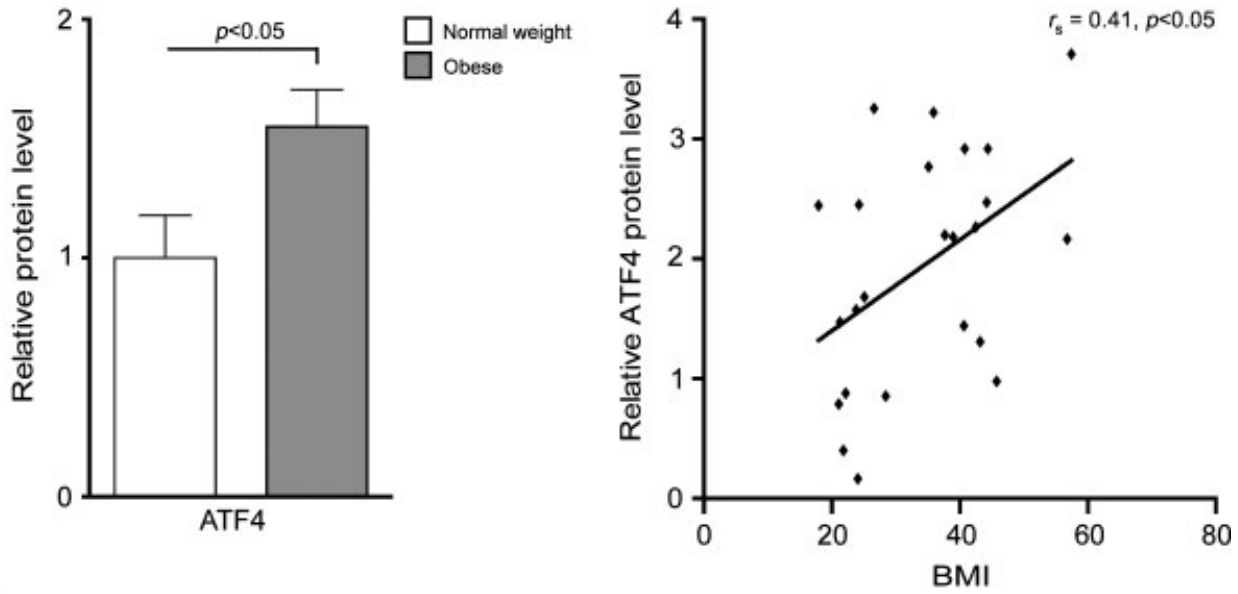

D

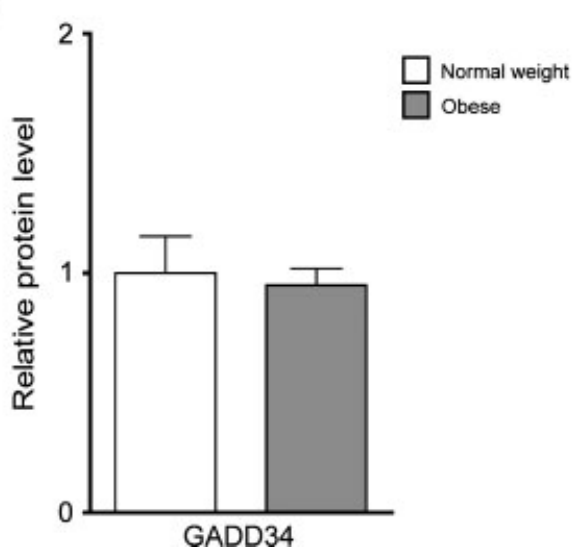

Figure 4. The UPR is activated in the jejunum of obese subjects. (A) Western blot analysis showed increased band density for BiP and ATF4 in obese samples (representative bands of three subjects per group). GADD34 levels did not differ between the study groups. Quantification of western blots demonstrated a significant $(p<0.05)$ up-regulation of both BiP ( $\mathrm{B}$, left panel) and ATF4 ( $\mathrm{C}$, left panel). No difference in GADD34 expression was observed (D). Both BiP (B, right panel) and ATF4 (C, right panel) concentrations correlated with $\mathrm{BMI}\left(r_{\mathrm{s}}=0.45\right.$, $p<0.05$ and $r_{\mathrm{s}}=0.41, p<0.05$, respectively). 
A

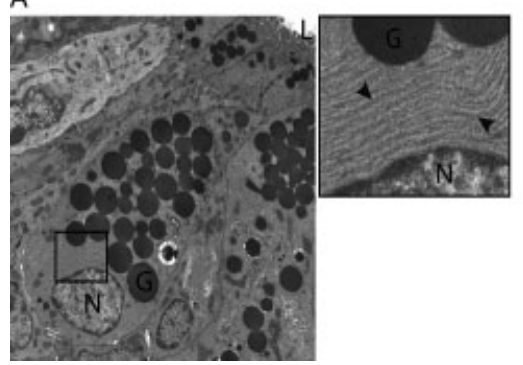

B

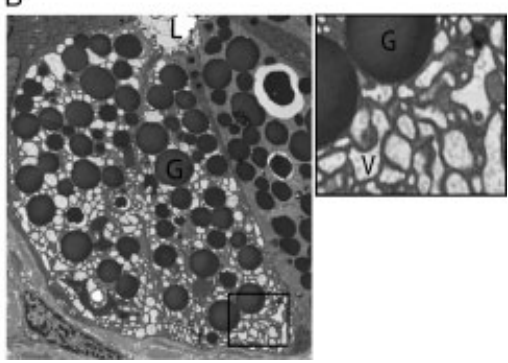

Figure 5. Expansion of the ER indicates ER stress in the Paneth cells of obese subjects. (A) Representative EM images of Paneth cells in the jejunum of normal weight subjects revealed a normally structured ER (arrowheads), while the ER in the Paneth cells of obese subjects displayed vacuoles $(V)$ and was expanded $(B)$, indicative of ER stress. $L=$ lumen; $N=$ nucleus; $G=$ granule.

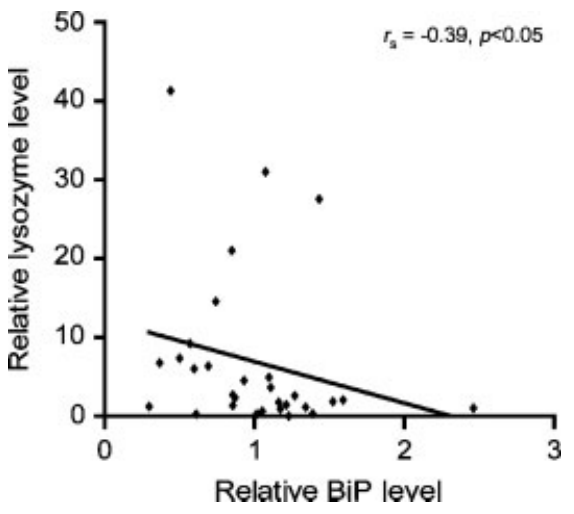

Figure 6. Activation of the UPR is associated with a reduction in lysozyme expression in the gut of obese subjects. BiP protein levels were correlated inversely with lysozyme protein levels $\left(r_{\mathrm{s}}=-0.39\right.$, $p<0.05)$.

The diminished antimicrobial protein expression and increased mRNA levels of their corresponding genes could be explained by a Paneth cell-depleting hypersecretory response to obesity. However, this seems improbable considering that during a chronic steady state, both enhanced mRNA and protein levels are expected. We therefore hypothesized the discordance between antimicrobial protein expression and mRNA expression in the Paneth cells of obese subjects to be a consequence of a translational block caused by ER stress. Paneth cells have been shown to be susceptible to ER stress, due to their highly secretory nature [24]. In addition, excessive nutrient intake, increased need for protein synthesis, and excess lipid accumulation associated with obesity are known to be chronic stimuli in causing ER stress [25-27]. The latter fact could, via its influence on intestinal microbiota, result in a vicious circle. In this regard, the UPR has been shown to be activated in both the liver and adipose tissue of obese subjects. Alternatively, it could be envisaged that the altered microbiota is causative for ER stress resulting in reduced Paneth cell antimicrobial expression. Here, we provide the first evidence for UPR activation in the gut of obese subjects. We show that obese subjects display increased protein levels of BiP, an important initiator of the UPR pathway, and of ATF4, a player in the PERK axis of the UPR, which is required for the induction of a translational block resulting in overall reduced protein synthesis [12]. It should be noted that goblet cells might contribute to these results since they are also susceptible to ER stress, although to a lesser extent than Paneth cells [24]. In addition, using EM, we observed indications of ER stress in the Paneth cells of obese subjects. Although we show clear activation of the UPR in the gut of obese subjects, downstream elements in the UPR pathway, including CHOP (data not shown) and GADD34, were unaltered. In support of our findings, it has been shown that adaptation to chronic ER stress induces persistent expression of $\mathrm{BiP}$ and other proteins concerned with alleviating protein folding stress, whereas the expression of both pro-apoptotic CHOP and GADD34 is unchanged [28]. These findings represent a fascinating aspect of the UPR: the ability to either facilitate adaptation to stress or induce apoptosis, depending on the nature and severity of the stressor. In obesity, a chronic condition, cells chronically exposed to ER stress must survive and adapt. Recent studies have provided insight into the mechanisms by which cells translate acute or chronic stress signals from the ER into a life-or-death response [28,29]. The involvement of such mechanisms in the gut of obese subjects is suggested by our findings that upstream players of the PERK pathway, constituting an adaptive response concerned with alleviating protein folding stress, are up-regulated, while pro-apoptotic CHOP and GADD34 are unchanged.

Our results, indicating a relationship between activation of the UPR in the small intestine and altered Paneth cell function, are supported by Kaser et al, who showed diminished antimicrobial protein secretion by Paneth cells in a mouse model displaying ER stress [24].

In conclusion, our findings provide important new insight into the involvement of Paneth cells in obesity. We identified these cells as a conceivable host factor responsible for the shift in microbiota composition accountable for many obesity-associated disorders. In addition, we show for the first time activation of the UPR in the intestine of obese subjects and indications of ER stress in Paneth cells, which may cause the observed Paneth cell compromise. Further studies on the role of altered Paneth cell function in relation to 
the obesity-associated intestinal microbiota shift are warranted.

\section{Acknowledgment}

We wish to thank Ronald M van Dam, MD, for collecting jejunal biopsies from normal weight subjects. We also thank Hans Duimel and Jordy Schreurs for their technical assistance, and Tine Comhair and Sonia Garcia for their expert advice on the UPR. This study was made possible by financial support of the 'Profilerings Fonds' of the Academic Hospital Maastricht, the Senter Novem Innovation oriented Research Program on Genomics: IOP Genomics IGE05012, and a Transnational University Limburg (TUL) Grant.

\section{Author contribution statement}

The authors contributed in the following way: $\mathrm{CMH}$, JG, SSR, WAB, JWG, and KL: study concept and design; FJV, JG, CHCD, and JWG: collection of clinical samples; $\mathrm{CMH}$ and $\mathrm{FKV}$ : acquisition of data; $\mathrm{CMH}$, FJV, JG, SSR, FKV, WAB, and KL: analysis and interpretation of data; $\mathrm{CH}$ : drafting of the manuscript; FJV, JG, SSR, CHCD, WAB, JWG, and KL: critical revision of the manuscript for important intellectual content.

\section{References}

1. Backhed F, Ding H, Wang T, et al. The gut microbiota as an environmental factor that regulates fat storage. Proc Natl Acad Sci U S A 2004; 101: 15718-15723.

2. Backhed F, Manchester JK, Semenkovich CF, et al. Mechanisms underlying the resistance to diet-induced obesity in germ-free mice. Proc Natl Acad Sci U S A 2007; 104: 979-984.

3. Turnbaugh PJ, Ley RE, Mahowald MA, et al. An obesityassociated gut microbiome with increased capacity for energy harvest. Nature 2006; 444: 1027-1031.

4. Ley RE, Backhed F, Turnbaugh P, et al. Obesity alters gut microbial ecology. Proc Natl Acad Sci U S A 2005; 102: 11070-11075.

5. Ley RE, Turnbaugh PJ, Klein S, et al. Human gut microbes associated with obesity. Nature 2006; 444: 1022-1023.

6. Salzman NH, Hung K, Haribhai D, et al. Enteric defensins are essential regulators of intestinal microbial ecology. Nature Immunol 2009; 11: 76-83.

7. Wehkamp J, Salzman NH, Porter E, et al. Reduced Paneth cell alpha-defensins in ileal Crohn's disease. Proc Natl Acad Sci U S A 2005; 102: 18129-18134.

8. Salzman NH, Ghosh D, Huttner KM, et al. Protection against enteric salmonellosis in transgenic mice expressing a human intestinal defensin. Nature 2003; 422: 522-526.

9. Mukherjee S, Vaishnava S, Hooper LV. Multi-layered regulation of intestinal antimicrobial defense. Cell Mol Life Sci 2008; 284: 3019-3027.

10. Vaishnava S, Behrendt CL, Ismail AS, et al. Paneth cells directly sense gut commensals and maintain homeostasis at the intestinal host-microbial interface. Proc Natl Acad Sci U S A 2008; 105: $20858-20863$.
11. Mastroianni JR, Ouellette AJ. Alpha-defensins in enteric innate immunity: functional Paneth cell alpha-defensins in mouse colonic lumen. J Biol Chem 2009; 284: 27848-27856.

12. Todd DJ, Lee AH, Glimcher LH. The endoplasmic reticulum stress response in immunity and autoimmunity. Nature Rev Immunol 2008; 8: 663-674.

13. Dudek J, Benedix J, Cappel S, et al. Functions and pathologies of BiP and its interaction partners. Cell Mol Life Sci 2009; 66: $1556-1569$.

14. Li Q, Zhang Q, Wang C, et al. Influence of alemtuzumab on the intestinal Paneth cells and microflora in macaques. Clin Immunol 2010; 136: 375-386.

15. Cani PD, Bibiloni R, Knauf C, et al. Changes in gut microbiota control metabolic endotoxemia-induced inflammation in high-fat diet-induced obesity and diabetes in mice. Diabetes 2008; 57: $1470-1481$.

16. Cani PD, Possemiers S, Van de Wiele T, et al. Changes in gut microbiota control inflammation in obese mice through a mechanism involving GLP-2-driven improvement of gut permeability. Gut 2009; 58: 1091-1103.

17. Li S, Wu WC, He CY, et al. Change of intestinal mucosa barrier function in the progress of non-alcoholic steatohepatitis in rats. World J Gastroenterol 2008; 14: 3254-3258.

18. Farhadi A, Gundlapalli S, Shaikh M, et al. Susceptibility to gut leakiness: a possible mechanism for endotoxaemia in non-alcoholic steatohepatitis. Liver Int 2008; 28: 1026-1033.

19. Brun P, Castagliuolo I, Di Leo V, et al. Increased intestinal permeability in obese mice: new evidence in the pathogenesis of nonalcoholic steatohepatitis. Am J Physiol Gastrointest Liver Physiol 2007; 292: 518-525.

20. Verdam FJ, Rensen SS, Driessen A, et al. Novel evidence for chronic exposure to endotoxin in human nonalcoholic steatohepatitis. J Clin Gastroenterol 2011; 45: 149-152.

21. Grootjans J, Hodin CM, de Haan JJ, et al. Level of activation of the unfolded protein response correlates with Paneth cell apoptosis in human small intestine exposed to ischemia/reperfusion. Gastroenterology 2011; 140: 529-539.

22. Sun L, Yu Z, Ye X, et al. A marker of endotoxemia is associated with obesity and related metabolic disorders in apparently healthy Chinese. Diabetes Care 2010; 33: 1925-1932.

23. Amar J, Burcelin R, Ruidavets JB, et al. Energy intake is associated with endotoxemia in apparently healthy men. Am J Clin Nutr 2008; 87: 1219-1223.

24. Kaser A, Lee AH, Franke A, et al. XBP1 links ER stress to intestinal inflammation and confers genetic risk for human inflammatory bowel disease. Cell 2008; 134: 743-756.

25. Ozcan U, Cao Q, Yilmaz E, et al. Endoplasmic reticulum stress links obesity, insulin action, and type 2 diabetes. Science 2004; 306: 457-461.

26. Boden G, Duan X, Homko C, et al. Increase in endoplasmic reticulum stress-related proteins and genes in adipose tissue of obese, insulin-resistant individuals. Diabetes 2008; 57: 2438-2444.

27. Sharma NK, Das SK, Mondal AK, et al. Endoplasmic reticulum stress markers are associated with obesity in nondiabetic subjects. J Clin Endocrinol Metab 2008; 93: 4532-4541.

28. Rutkowski DT, Arnold SM, Miller CN, et al. Adaptation to ER stress is mediated by differential stabilities of pro-survival and pro-apoptotic mRNAs and proteins. PLoS Biol 2006; 4: e374.

29. Rutkowski DT, Kaufman RJ. That which does not kill me makes me stronger: adapting to chronic ER stress. Trends Biochem Sci 2007; 32: 469-476. 
SUPPORTING INFORMATION ON THE INTERNET

The following supporting information may be found in the online version of this article.

Supplementary materials and methods.

Table S1. Primers used for qPCR assays. 